\title{
Magnetic resonance imaging in central pontine myelinolysis
}

\author{
P D THOMPSON, D MILLER, R F GLEDHILL, M N ROSSOR
}

From the University Department of Neurology, King's College Hospital Medical School and the Institute of Psychiatry, and the University Department of Clinical Neurology, Institute of Neurology, The National Hospital for Nervous Diseases, London, UK.

SUMMARY Magnetic resonance imaging (MRI) was performed in two patients in whom a clinical diagnosis of central pontine myelinolysis (CPM) had been made. MRI showed lesions in the pons in both cases about 2 years after the illness, at a time when the spastic quadriparesis and pseudobulbar palsy had recovered. The persisting abnormal signals in CPM are likely to be due to fibrillary gliosis. Persistence of lesions on MRI means that the diagnosis of CPM may be made electively, after the acute illness has resolved.

Central pontine myelinolysis (CPM) is a descriptive term for a distinct pathological entity in which primary demyelination of the basis pontis is the dominant feature.' Although formerly considered a rare condition, there have been numerous reports of cases fulfilling the pathological criteria for the diagnosis of CPM ${ }^{2}$ while recent clinical descriptions have suggested that it may be more common than previously recognised. ${ }^{34} \mathrm{~A}$ major problem in the diagnosis of CPM in life has been the reliance on clinical criteria. Computed tomography of the brain ${ }^{5-10}$ and brainstem evoked potentials ${ }^{5}$ may indicate pontine abnormalities, but magnetic resonance imaging $(\mathrm{MRI})^{11-22}$ has shown quite distinctive changes. Moreover these may persist for some time after the illness. The purpose of this paper is to draw attention to the nature and significance of these persistent changes.

\section{Case reports}

The presenting clinical features of these two patients have been reported in detail previously ${ }^{3}$ and only a brief summary will be given here.

Case 1. An 18 year old woman presented in the 20 th week of her second pregnancy with hyperemesis gravidarum. Admis-

Address for reprint requests: Dr P D Thompson, Department of Clinical Neurology, Institute of Neurology, The National Hospital for Nervous Diseases, Queen Square, London WCIN 3BG, UK.

Received 28 October 1988.

Accepted 28 November 1988 sion values for serum sodium and urea were $126 \mathrm{mmol} / \mathrm{l}$ and $86.5 \mathrm{mmol} / \mathrm{l}$, respectively. Over the subsequent 2 days she was given 101 of $0.9 \%$ sodium chloride and 61 of $5 \%$ dextrose water. These measures corrected the serum sodium to $145 \mathrm{mmol} / \mathrm{l}$ and the urea to $14.7 \mathrm{mmol} / \mathrm{l}$. Four days later she became anarthric. The next day she was irritable and

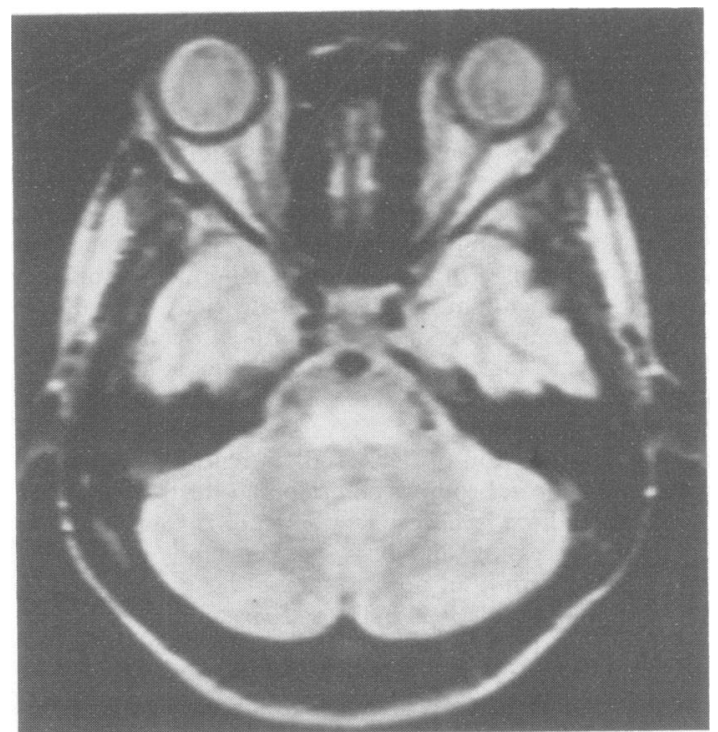

Fig 1 (Case 1): $5 \mathrm{~mm}$ axial and sagittal slices of the brain and brain stem obtained with a Picker 0.5 Tesla MR scanner using a spin-echo sequence (SE 2000/60). There is a well defined area of high signal in the central pons. 


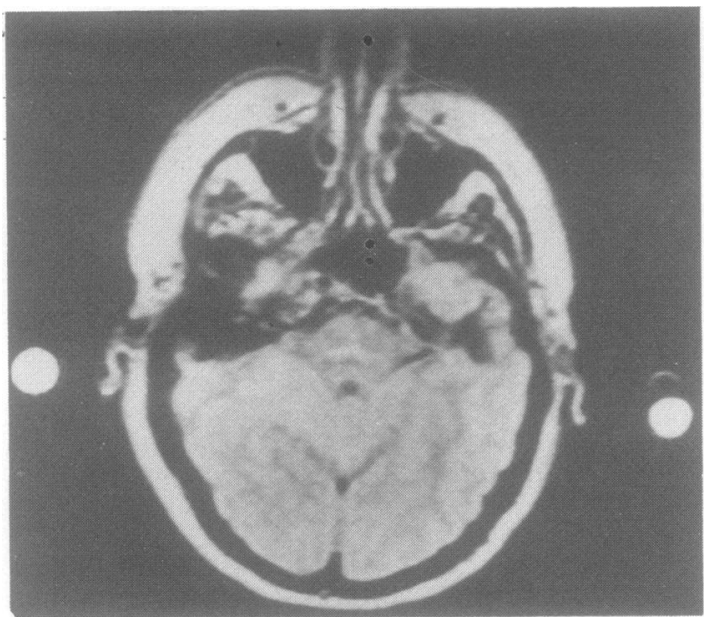

Fig 2 (Case 2): Axial MR scans of brain stem as described in fig 1. The area of abnormal signal in the pons in this case shows a "butterfly" pattern (see text).

confused with bilateral 6 th cranial nerve palsies and horizontal nystagmus. Wernicke's encephalopathy was diagnosed and parenteral thiamine, $250 \mathrm{mg}$, was administered. By the following day the abnormal ocular movements had improved, though there was now bilateral lower facial weakness and a left extensor plantar response. A spastic quadriparesis without sensory change evolved over the ensuing 2 weeks. These neurological deficits subsequently improved and 8 weeks after admission she was independent for daily activities.

At 37 weeks gestation she was delivered of a healthy male infant whose subsequent development has been normal.

MRI was performed 20 months after the illness, at which time clinical examination was normal. A well defined area of abnormal signal was present in the basis pontis sparing the ventral pons (fig 1).

Case 2. A 52 year old woman presented with drowsiness and a 1 week history of vomiting and diarrhoea. Her daily medication for hypertension included chlorthalidone, spironolactone, and cyclopenthiazide. She adhered strictly to a salt free diet. On examination she was confused, without other abnormal neurological signs. Shortly after admission she suffered a generalised seizure. The serum sodium was $99 \mathrm{mmol} / \mathrm{l}$. Over the next 3 days she received 21 of $2 \%$ sodium chloride, 2.51 of $0.9 \%$ sodium chloride, parenteral frusemide, and oral sodium chloride and dextrose powder. The serum sodium level rose to $123 \mathrm{mmol} / \mathrm{l}$. Thereafter, she developed increasing difficulty speaking and moving her limbs. One month after admission she was observed to be alert with a pseudobulbar palsy and spastic quadriparesis. Sensation was intact. During the following 2 months she improved and was mobile and independent at discharge.

When examined 2 years later, she exhibited slight dysarthria and mobile dystonic posturing of both upper limbs, left more than right. Deep tendon reflexes were symmetrically brisk. Her gait was wide-based and she was unable to walk heel-to-toe.

MRI revealed an area of abnormal signal in the pons (fig
2). Scattered abnormal signals also were evident in the cerebral white matter. These could have been associated with her preceding hypertension or extra-pontine myelinolysis. No lesions were identified in the basal ganglia or thalamus.

\section{Discussion}

The site, shape and size of the lesions in CPM demonstrated by MRI are identical to those described in pathological specimens. There may be large symmetrical lesions in the basis pontis, usually sparing the ventral pons, ${ }^{211-23}$ or there may be smaller, "butterfly" or "trident" shaped lesions in the base of the pons as in case 2 (fig 2). ${ }^{192}$

These lesions of CPM, visualised by MRI, have now been reported by many authors, ${ }^{11-23}$ and demonstrated at intervals ranging from weeks to months after resolution of the acute illness. In the two cases presented in this report, the lesions were still evident 20 and 24 months after recovery, at a time when one of the patients was normal on clinical examination. The nature of such persisting lesions is worthy of further comment.

Lesions are visualised on MRI largely because of an increase in tissue water proton content. ${ }^{25}$ The cardinal pathological change of CPM is loss of myelin with preservation of axons, in the absence of a significant inflammatory reaction..$^{12}$ In the chronic lesion, intense fibrillary gliosis has been observed. ${ }^{2}$ Loss of myelin? per se, is unlikely to affect the MRI signal since the lipid protons in myelin make a negligible contributio to the normal brain signal. ${ }^{26}$ On the other hand, the proliferation of astrocytes (with their abundant cytoplasm) in areas of gliosis would result in an increase in tissue water content per unit volume. As the signals in normal brain are produced by water protons,${ }^{26} \mathrm{it}$ seems likely therefore that gliosis is making an important contribution to the MRI signal in the chronic lesion. The clinical recovery in the face of such gliosis is noteworthy.

The observation that residual gliosis after CPM may remain visible on MRI long after the critical phases of the illness, and when neurological deficits have improved or recovered, has several implications. The most important of these is that elective scanning may yield diagnostic information in patients suspected of having CPM. Thus, patients may be scanned when their clinical state permits, after the acute illness has resolved. Furthermore, it provides opportunity to obtain a clearer picture of the incidence of this condition, and may help resolve the controversy surrounding its aetiology and pathogenesis, particularly in relation to the treatment of hyponatraemia. ${ }^{327}$

Finally, the persistence of the MRI signals in CPM with clinical recovery must be taken into account when 
interpreting MRI appearances in the context of a subsequent, unrelated illness.

\section{References}

1 Adams RD, Victor M, Mancall EL. Central pontine myelinolysis. Arch Neurol Psychiat 1959;81:154-72.

2 Wright DG, Laureno RD, Victor M. Pontine and extrapontine myelinolysis. Brain 1979;102:361-85.

3 Thompson PD, Gledhill RF, Quinn NP et al. Neurological complications associated with parenteral treatment: central pontine myelinolysis and Wernicke's encephalopathy. $\mathrm{Br}$ Med J 1986;292:684-5.

4 Sterns RH, Riggs JE, Schochet SS Jr. Osmotic demyelination syndrome following correction of hyponatraemia. $N$ Engl $J M e d$ 1986;314:1535-42.

5 Telfer RB, Miller EM. Central pontine myelinolysis: demonstration by computerised tomography. Ann Neurol 1979;6:455-6.

6 Anderson TL, Moore RA, Grinnell SH, Itabashi HH. Computerised tomography in central pontine myelinolysis. Neurology 1979;29:1527-30.

7 Thompson DS, Hutton JT, Stears JC, Sung JH, Norenberg MD. Computerised tomography in the diagnosis of central and extrapontine myelinolysis. Arch Neurol 1981;38:243-6.

8 Hazratji SMA, Kim RC, Lee SH, Marasigam AV. Evolution of pontine and extrapontine myelinolysis. J Comput Assist Tomogr 1983;7:356-71.

9 Gerber O, Geller M, Shiller J, Yang W. Central pontine myelinolysis. Resolution shown by computed tomography. Arch Neurol 1983;40:116-8.

10 Sztencel J, Baleriaux D, Bovenstein S, Brunko E, Zegers de Beyl D. Central pontine myelinolysis; correlation between CT and electrophysiological data. AJNR 1983;4:529-30.

11 DeWitt LD, Buonanno FS, Kistler JP et al. Central pontine myelinolysis: demonstration by nuclear magnetic resonance. Neurology 1984;34:570-6.

12 Rosenbloom S, Bucholz D, Kumar AJ et al. Evolution of central pontine myelinolysis AJNR 1984;5:110-2.

13 Schroth G. Clinical and CT confirmed recovery from central pontine myelinolysis. Neuroradiology 1984;26:149-51.
14 Takeda K, Sakuta M, Saeki F. Central pontine myelinolysis diagnosed by magnetic resonance imaging. Ann Neurol 1985;17:310-1.

15 Price BH, Mesulam MM. Behavioural manifestations of central pontine myelinolysis. Arch Neurol 1987;44:671-3.

16 Price DB, Kramer J, Hotson GC, Loh JP. Central pontine myelinolysis: report of a case with distinctive appearance on MRI imaging. AJNR 1987;8:576-7.

17 Gerard E; Healy ME, Hesselink JR. MR demonstration of mesencephalic lesions in osmotic demyelination syndrome (central pontine myelinolysis). Neuroradiology 1987;29:582-4.

18 Redmund J, Brunner J, Haggar A, Elias S. Central pontine myelinolysis: evolution following correction of acute hyponatraemia shown by MRI. Neurology 1987;37(Suppl 1):306.

19 Dickoff DJ, Raps M, Yahr MD. Striatal syndrome following hyponatraemia and its rapid correction. A manifestation of extrapontine myelinolysis confirmed by magnetic resonance imaging. Arch Neurol 1988;45:112-4.

20 Brunner JE, Redmond JM, Haggar AM, Elias SB. Central pontine myelinolysis after rapid correction of hyponatraemia: a magnetic resonance.imaging study. Ann Neurol 1988;23:389-91.

21 Steller U, Koschorek F, Strenge H. Cerebellar ataxia with recovery related to central pontine myelinolysis. J Neurol 1988;235: 379-81.

22 Thompson AJ, Brown MM, Swash M, Thakkar C, Scholtz C. Autopsy validation of MRI in central pontine myelinolysis. Neuroradiology 1988;30:175-7.

23 Bearcroft CP, Metcalfe K, McCarthy MI, Almond MK, Chong MS, Hitman GA. Clinical heterogeneity of central pontine myelinolysis. Lancet 1988;ii:688.

24 Tomlinson B, Pierides A, Bradley W. Central pontine myelinolysis. Two cases with associated electrolyte disturbance. $Q J$ Med 1976;40:373-86.

25 Ormerod IEC, Miller DH, McDonald WI et al. The role of NMR imaging in the assessment of multiple sclerosis and isolated neurological lesions. A quantitative study. Brain 1987; 110:1579-1616.

26 Bottomley PA, Hart HR, Edelstein WA et al. Anatomy and metabolism of the normal human brain studied by magnetic resonance at 1.5 tesla. Radiology 1984;150:441-6.

27 Illowsky BP, Laureno R. Encephalopathy and myelinolysis after rapid correction of hyponatraemia. Brain 1987;110:855-67. 